\title{
TRAINING PhDs IN EDUCATION ON RESEARCH METHODOLOGY
}

\author{
Svitlana Sysoieva \\ Doctor of Sciences in Pedagogy, Professor \\ Full Member (Academician) of the National Academy of Educational Sciences of Ukraine \\ Head of Scientific Research Laboratory of Educology \\ Borys Grinchenko Kyiv University, Ukraine \\ s.sysoieva@kubg.edu.ua \\ $+380444268405$ \\ ORCID ID 0000-0003-2499-732X
}

\begin{abstract}
On the basis of studying the US experience on the content of training PhDs in education the author presents the program on research methodology in education for training PhDs in education. The purpose of the course is to develop future scientists methodological culture, integrated system of scientific knowledge, the ability to organize and conduct research in the field of education, including disciplinary and interdisciplinary research, and it is aimed at forming a system of research competencies.

Keywords: PhD in education; research methodology.
\end{abstract}

\section{INTRODUCTION}

According to the law "On Higher Education" of Ukraine (2014) training PhD in education corresponds to the third (education and research) level of higher education. In Ukraine, the main form of preparation of scientific and pedagogical personnel of higher qualification is postgraduate education at the university. That is why today postgraduate educational institutions of Ukraine carry out a considerable work to determine the content of training future $\mathrm{PhDs}$ in education. As the study of the US experience shows, considerable attention in the preparation of PhDs in education should be given to mastering research methods (quantitative, qualitative, mixed), organizing and carrying out the experiment, definition of its probability, mathematical statistics methods. It is believed that such training should be provided from general (general scientific methodology) to partial (specific scientific methodology) to all doctoral students regardless of the nature of research (theoretical and experimental, comparative, historical, etc.) (Sysoieva S., 2016). We fully share the attention to the development of methodological culture of future PhDs and we believe that in the training of doctors of philosophy in education the question of methodology should be central.

The purpose of this paper is to reveal the content of the program on research methodology in education and forms of learning.

\section{TEACHING RESEARCH METHODOLOGY IN EDUCATION OF PHD}

On the basis of study of the US experience in training of PhDs in education we have developed and experimentally implemented a training program on the subject "Methodology of Research in Education" for training of PhDs in education. The program was developed based on education and research training program 
for PhDs according to the curriculum of Borys Grinchenko Kyiv University. The program aims to train future $\mathrm{PhDs}$ in education to research activities, development of necessary competencies for such activities, mastering the methodology of research in the field of education, and therefore the goal of the training course "Methodology of Research in Education" is to develop future scientists methodological culture, integrated system of scientific knowledge, the ability to organize and conduct research in the field of education, including disciplinary and interdisciplinary. The task is formulated on the basis of competence approach:

- the formation of a scientific outlook and methodological culture, development of intelligence, artistic qualities, capacity for research and innovation in education;

- development of methodological competence (understanding of modern methodology of education, the ability to use methods of scientific knowledge, conducting research activities, development and implementation of research projects, conducting disciplinary and interdisciplinary research in education);

- mastering research competence (commitment to scientific research, the ability to own methodology and methods of teaching experiment, identifying goals, objectives, strategy, research activities, the introduction of new educational technologies in their own research activities, generating new ideas);

- mastery of information competence (the ability to analyze information from different sources; professional have basic methods, ways and means of acquisition, storage and processing; effective use of multimedia technology).

To perform the tasks of training research methodology in education we consider it is important to focus on gaining the following knowledge the by future PhDs: the classification of research in the field of education; disciplinary and interdisciplinary research; design methodology of scientific research; selection of research methods; quantitative and qualitative research methods in education; methods of mathematical statistics; requirements to the results of research in education. For improving the quality and efficiency of course study the program provides lectures, practical tasks related to the topic of study and seminars, aimed at the development of future $\mathrm{PhD}$ systems competencies. The quality of a $\mathrm{PhD}$ in education can be seen in two aspects: procedural, a set of properties and characteristics of the educational process that gives it the ability to form a professional level competence, that meets the needs of citizens, education, "society and state" (Sysoieva S., 2016: p. 9; 12) and personality as a system of acquired and assigned competencies. Under this system we understand the following:

1. pedagogical (acquiring the ability to handle scientific terminology in the field of education to understand the consistency, integrity and interrelation of different educational phenomena and processes focus in modern legal framework of education, educational policy trends in Ukraine to apply comparative analysis in the research, summarize pedagogical innovation experience);

2. methodological (ability to plan and organize scientific activities in the field of education adequately apply scientific methods in research; implement ICT;

3. diagnostic (the ability to monitor results; evaluate the results of experimental work, assess the scientific and practical value of the study);

4. personality-transforming (the ability to study and modernization of existing reared systems and technologies, understanding the processes of personality formation in the process of education and self-education, to analyze socio-cultural environment, problems of education of the individual at different age stages; implement value-semantic approach to education of children and youth). 
The program was developed taking into account regulation documents and the author's works. It should be noted that the number of hours for this course includes 60 hours (two credits), out of which 16 hours are lectures; 12 hours are seminars. 32 hours are provided for individual work. At the end of the course a colloquium is held. The program is module-based and it comprises three modules: research in education; organization of research in the field of education; analysis of research in the field of education. Here is the content of each module.

Topics of the lectures of the first module include two themes: the concept of methodology, classification of research in the field of education; disciplinary and interdisciplinary studies. In studying the topic "The concept of methodology. Classification of research in the field of education covers the following issues: the concept of methodology, methodology of science, methodological culture; research in the field of education as a process and the result of scientific research; classification of research according to their nature and content; basic and applied research; theoretical and experimental research; collective research; approaches to scientific investigation: disciplinary, interdisciplinary, multidisciplinary (multidisciplinary) and transdisciplinary; requirements for scientific research; program development research.

The basic concepts of topics are identified: methodology, methodology of science, methodological culture, scientific research, research in the field of education, basic research, applied research, theoretical research, experimental research, collective research, disciplinary approach, interdisciplinary approach, multidisciplinary approach, transdisciplinary approach, research methodology program of scientific research.

In studying the second theme of the first module "Disciplinary and Interdisciplinary Studies" considered are the following issues: the nature of the disciplinary approach to scientific research; methodology disciplinary research in the field of education; interdisciplinary scientific research as a process and the result of integration of various branches of scientific knowledge; signs of interdisciplinary research; types and classification of interdisciplinary research; common and different disciplinary and interdisciplinary research in the field of education; the main provisions of interdisciplinary research methodologies; examples of interdisciplinary research in education.

The main concepts of the themes are: disciplinary approach, interdisciplinary approach, disciplinary scientific research, interdisciplinary scientific research, multidisciplinary scientific research, transdisciplinary scientific research, interdisciplinary research methodology.

Seminar "Basic approaches to research in the field of education" that accompanies the study of the second theme of the first module includes two parts: a theoretical and academic discussion. In the theoretical part of the seminar, for which no more than 20 minutes are provided, the given questions are repeated: conceptual themes and terminology; the nature and content of a disciplinary approach, interdisciplinary, multidisciplinary (multidisciplinary) approach to research, and establishes the concept of "transdisciplinarity" and "transdisciplinary scientific research." Academic discussion is held in the form of discussion of theoretical issues that directly affect specific topics of research students.

The study of the second module "research organization in the field of education" examines three themes that consistently reveal the following topics: design methodology of scientific research; general description of methods of research; quantitative methods in education; qualitative methods in education. 
In studying this module, the students gradually deepen their knowledge in the basic methodological characteristics of studies in the field of education; stage design research; its goals and objectives, hypotheses of the study; reliability (probability survey results); object protection.

A certain number of issues related to research methods includes: the problem of classification methods of scientific research in the field of education; general scientific methods; partially scientific methods; special methods; methods of processing the results of research; theoretical, empirical, sociological methods and techniques of mathematical statistics; quantitative, qualitative and mixed methods; selection methods for disciplinary and interdisciplinary research in the field of education.

Certain topics, such as quantitative and qualitative research methods in education, including the use of quantitative methods in education are considered as different ones: processing of observations and experiments; modelling, diagnosis, prognosis, etc.; such quantitative research methods as content analysis, experiment, questionnaires methods (surveys, interviews, surveys), the method of independent peer review, sociometric techniques; statistical method; qualitative methods: direct or unclassified (focus groups and depth interviews); indirect or secret (focus groups, depth interviews and projective techniques: associative, completion situation, design a situation expressive).

In the study of the second module provided are four seminars on the following topics: "Methodological bases of research in the field of education", discussing the basic stages of designing experimental work in the field of education; "Interdisciplinary research methods in education", discussing the system of interdisciplinary research methods in education and its practical application; "Methods of empirical research" and "methods of theoretical research" in the context of specific themes of research students.

In studying of the third module "Analysis of research in the field of education" two topics are discussed: "Methods of Mathematical Statistics" and "Requirements of research results."

The basic concepts of the first theme are defined: measurement in education, measuring scale, grouping data variation, normal distribution, variation range, distribution curve, mathematical statistics, the representativeness of the sample, standard error, Student's test, Fisher's criterion, the criterion of Pearson, the measure communication between variables correlation criterion rank statistical test a scientific hypothesis, the probability of the results, multidimensional analysis techniques, factor analysis, variance analysis, regression analysis, statistical data processing, graphical representation of the survey results, range, histogram and etc.

Among the requirements for the results of the study are considered requirements for the content of research material; requirements for the structure of scientific research in the field of education; contents, introduction, main body, conclusion, applications; to scientific papers and reports; testing and implementation of research results.

The third module includes the seminar "Measurement in Education", in which, in practical terms, considered are basic concepts of mathematical statistics; examples of using Student's test and Fisher criterion during the processing of the study. Much attention during the course study is paid to individual work and consultations on its implementation. Individual work is planned for each topic and is directed to the students' research topic. 
As examples, we can show the following tasks for individual work: to reveal the methodology of your research on the philosophical, general scientific, specific scientific and technological levels; analyze that character of your research: disciplinary or interdisciplinary; design your research, identify stages of the research work, formulate intermediate targets; make the selection of research methods for your scientific work and their classification; discover the essence of quantitative methods that you plan to use in your research, etc.

\section{CONCLUSIONS}

The training of scientific and scientific-pedagogical staff shows that the greatest difficulty young scientists experience in conducting experimental work, justifying their own position regarding scientific aspects of the research and scientific approaches of other scientists. That is why we believe that the methodology research rate in education should maximize the development of independent critical thinking, the ability to justify their own scientific point of view, learn the works of great scientists in methodology of pedagogy and education in general.

\section{REFERENCES}

1. Sysoieva, S., Mospan, N. (2015). New Law on Higher Education in Ukraine: Innovations and Risks. Didactica Slovenica, 30 (3-4), 166-179. Retrieved from http://www.pedagoska-obzorja.si/revija/Vsebine/PDF/DSPO_2015_30_03.pdf

2. Poberezska, G. (2005). Trends in higher education in Westerm Europe and Ukraine, dissertation: 13.00.01 / APS of Ukraine; Institute of Higher Education. Kyiv.

3. Sysoieva, S. Methodology of Research in Education: program (for training of PhD in education specialty 13.00.04 - theory and methods of professional education). Kyiv. Borys Grinchenko Kyiv University.

4. Sysoieva, S. (2016). Training PhDs in education: the experience of leading universities. Kyiv: Ridna shkola, 5-6, 12-18. 